\title{
Revue Gouvernance
}

Governance Review

\section{Lettre du rédacteur en chef \\ Letter from the Editor}

\section{Christian Rouillard}

Volume 6, numéro 2, 2009

URI : https://id.erudit.org/iderudit/1039076ar

DOI : https://doi.org/10.7202/1039076ar

Aller au sommaire du numéro

Éditeur(s)

Centre d'études en gouvernance de l'Université d'Ottawa

ISSN

1912-0362 (numérique)

Découvrir la revue

Citer ce document

Rouillard, C. (2009). Lettre du rédacteur en chef. Revue Gouvernance /

Governance Review, 6(2). https://doi.org/10.7202/1039076ar d'utilisation que vous pouvez consulter en ligne.

https://apropos.erudit.org/fr/usagers/politique-dutilisation/ 


\title{
Lettre du rédacteur en chef
}

\author{
Vol.6, No. 2, janvier 2010, Page 1
}

Ce dernier numéro de 2009 est également le dernier numéro sous ma direction en tant que Rédacteur en chef. Après maintenant cinq ans à la barre de Revue gouvernance, je serai remplacé par deux collègues du programme d'administration publique de l'École d'études politiques, à savoir les professeurs Louis Simard et Frank Ohemeng. Aucun doute qu'ils vont offrir une énergie renouvelée à la revue et possiblement l'amener sur des terres qui lui sont pour le moment inconnues!

Disponible en ligne depuis le printemps 2004, Revue gouvernance a développé un membership de plus de 2000 universitaires et praticiens, au Canada et ailleurs dans le monde, intéressés par l'administration publique et les questions touchant la gouvernance des organisations publiques et privées. Avec le membership combiné d'Optimum Online(sa revue compagnon moins théorique), Revue gouvernance offre à ses auteurs un lectorat potentiel de plus de 10000 personnes à travers le monde!

Bonne lecture et Joyeuses Fêtes!

Christian Rouillard

Rédacteur en chef, 2004-2009 